\title{
Jejunal perforation secondary to metastatic bronchogenic carcinoma
}

\author{
A.R. Quayle, S. Holt and R.G. Clark
}

The University Surgical Unit, Clinical Sciences Centre, Northern General Hospital, Sheffield, S5 7AU, UK.

\begin{abstract}
Summary: A case of peritonitis secondary to the perforation of a bronchogenic small bowel metastasis is reported. To our knowledge this is only the fourth case in which peritonitis was the presenting feature of a squamous cell carcinoma of the bronchus. The publications to date are reviewed and the need to biopsy every small bowel perforation found at laparotomy is stressed.
\end{abstract}

\section{Introduction}

Peritonitis as a presenting feature of bronchogenic carcinoma following the perforation of a small bowel metastasis is rare. This is a report of such a case with a review of previous publications.

\section{Case report}

The patient was a 78 year old man who gave a $5 \mathrm{~h}$ history of severe generalized abdominal pain of sudden onset. On abdominal examination he was found to have generalized tenderness, associated with guarding and absent bowel sounds. A portable chest X-ray showed collapse of the left upper lobe; abdominal Xray was unremarkable. A diagnosis of peritonitis was made.

At laparotomy he was found to have a purulent peritonitis secondary to a solitary perforation of the jejenum $45 \mathrm{~cm}$ distal to the duodeno-jejunal flexure. Slight stricturing was noted at the site of the perforation but no definite lesion could be identified. Examination of the remaining intra-abdominal structures revealed no abnormality. Ten centimetres of small bowel were resected and continuity restored with an end to end anastomosis. Post operatively he had a swinging pyrexia and a further chest X-ray on the fourth post operative day showed persistent collapse of the left upper lobe with a left hilar mass. On the fifth post-operative day the patient developed a right hemiparesis. Over the next $48 \mathrm{~h}$ his condition deteriorated and he died.

The histology report on the resected jejunum surpr-

A.R. Quayle, M.B., F.R.C.S.; S. Holt, M.D.; R.G. Clark, M.B., F.R.C.S.

Correspondence: A.R. Quayle.

Accepted: 15 December 1983 isingly stated that there were clumps of squamous carcinoma within the lymphatics of the submucosa and serosa, particularly around the site of the perforation. No mucosal tumour was found (Figure 1). It was concluded that a secondary deposit from a bronchial squamous cell carcinoma had perforated. Unfortunately permission for a post mortem was refused.

\section{Discussion}

Although 9 previous cases of perforated small bowel due to metastatic bronchogenic carcinoma have been reported, in only 3 cases, as in the present case, was the perforation the presenting feature (Wellman et al., 1969; Ejeckam et al., 1979; Sternberg et al., 1980), the primary tumour having previously been diagnosed in the remaining 6 cases (Morgan et al., 1961; Wooten et al., 1967; Midell \& Lochman, 1972; Inalsingh et al., 1974; Ramanathan et al., 1976; Winchester et al., 1977).

The age of the 9 patients ranged from 36 to 81 years, with 7 males. The occurrence of small bowel metastases does not appear to be related to the histological type of the primary tumour, 4 of the 9 cases and the present case had squamous cell carcinomas and the remainder had undifferentiated carcinomas. This contrasts with the findings of 125 post-mortem examinations of patients with bronchogenic carcinoma in which only $38 \%$ of patients with squamous carcinoma showed tumour spread beyond the thorax, whereas $56 \%$ of patients with adenocarcinoma and $79 \%$ with undifferentiated carcinoma produced extrathoracic metastases (Weiss \& Gillick, 1977). Our own case and 6 of the previous cases had no other signs of metastatic disease within the abdominal cavity at laparotomy, although one patient developed ascites and died 10 


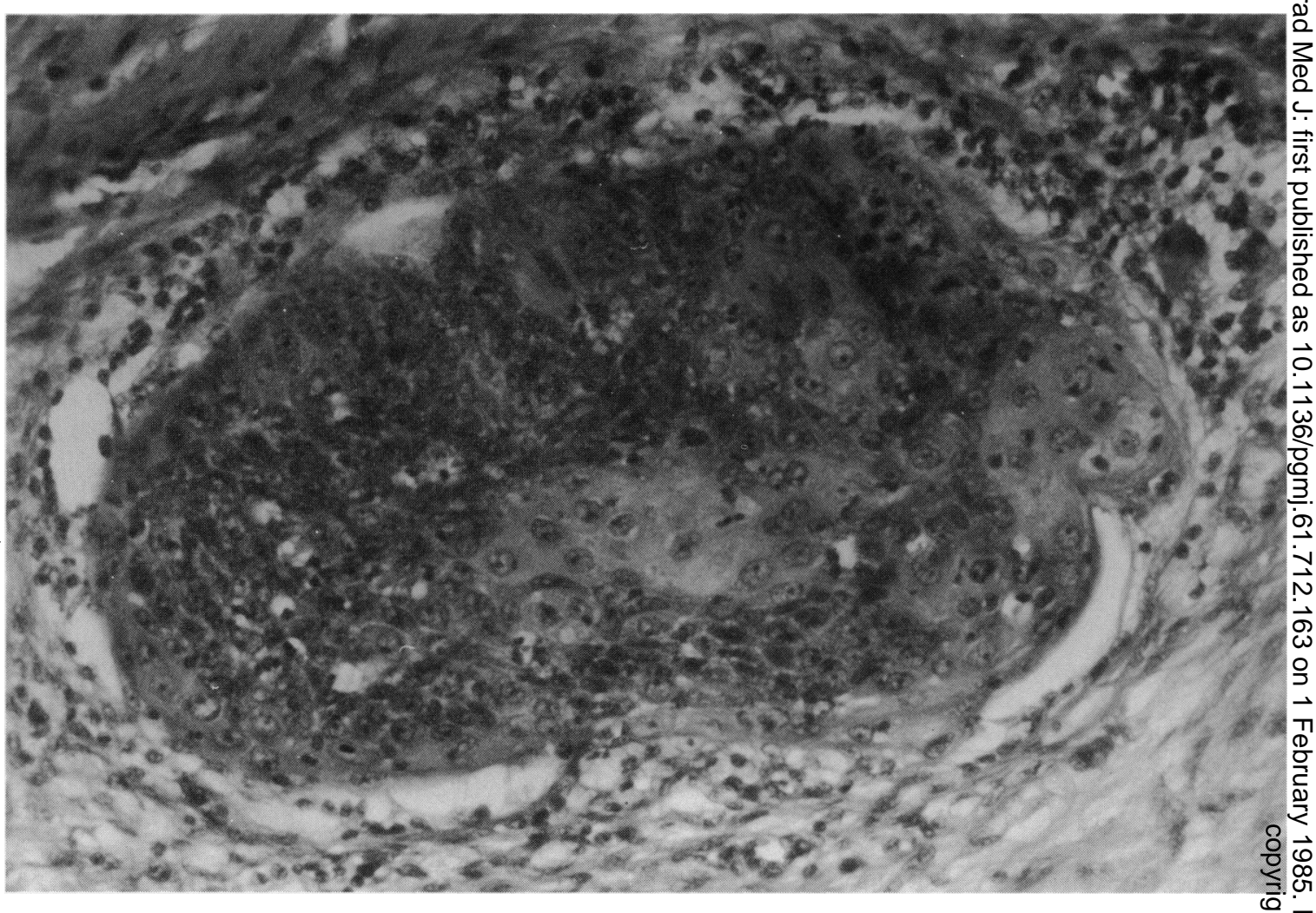

Figure 1 A section of small intestine showing a clump of tumour cells within a submucosal lymphatic displaying marked squamous differentiation. (H \& E $\times 295)$

weeks post-operatively (Wooten et al., 1967). Only 1 of the 9 cases survived more than 16 weeks following the small bowel perforation. It is therefore a late event in the disease and as a result chemotherapy is unlikely to be beneficial. It is noteworthy that perforation followed chemotherapy in one patient (Morgan et al., 1961).

The rarity of a bronchial tumour being the primary source is demonstrated by DeCastro's series of 51 cases of small bowel metastatic disease (DeCastro et al., 1957), none of which had primary bronchial carcinomas. DeCastro's unpublished Master's Thesis (quoted by Ejeckam et al., 1979) contained only one case of small bowel metastases with a primary tumour of the lung. In a further series of 14 cases, again only one patient had a primary lung carcinoma and only $5 \stackrel{\circ}{\frac{0}{2}}$ cases presented with perforation of the small bowel, $\overrightarrow{\vec{O}}$ the remainder presenting with small bowel obstruction 3 (Farmer \& Hawk, 1964).

We have reported the fourth case of small bowel perforation secondary to metastatic bronchogenic음 carcinoma which occurred before the primary lung.carcinoma had been diagnosed. Furthermore, in this 3 case the perforated jejunum did not appear to be involved with tumour at operation. We therefore $\frac{\mathrm{O}}{3}$ stress the importance of taking a biopsy from the site of perforation or resecting the perforated bowel for histological examination rather than carrying out a $\frac{}{8}$ simple oversewing procedure when a small bowel perforation is found at laparotomy. 


\section{References}

DeCASTRO, C.A., DOCKERTY, M.B. \& MAYO, C.W. (1957). Metastatic tumours of the small intestines. Surgery Gynecology and Obstetrics, 105, 159.

EJECKAM, G.C., ABELE, R., THOMAS, J. \& HERINGER, R. (1979). Abdominal crisis due to metastasizing lung carcinoma to the small bowel. Canadian Journal of Surgery, 22, 351.

FARMER, R.G. \& HAWK, W.A. (1964). Metastatic tumours of the small bowel. Gastroenterology, 46, 496.

INALSINGH, C.H.A., HAZRA, T. \& PREMPREE, T. (1974). Unusual metastases from carcinoma of the lung. Journal of the Canadian Association of Radiology, 25, 243.

MIDELL, A.I. \& LOCHMAN, D.J. (1972). An unusual metastatic manifestation of a primary bronchogenic carcinoma. Cancer, 30, 806.

MORGAN, M.W., SIGEL, B. \& WOLCOTT, M.W. (1961). Perforation of a metastatic carcinoma of the jejenum after cancer chemotherapy. Surgery, 49, 687.

RAMANATHAN, T., SKENE-SMITH, H., SINGH, D. \& SIVANESON, S. (1976). Small intestinal perforation due to secondaries from bronchogenic carcinoma. British Journal of Diseases of the Chest, 70, 121.

STERNBERG, A., GILER, S., SEGAL, I., SHMUTER, Z. \& KNOTT, I. (1980). Small bowel perforation as the presenting symptom of squamous cell carcinoma of the lung. Clinical Oncology, 6, 181.

WEISS, W. \& GILLICK, J.S. (1977). The metastatic spread of bronchogenic carcinoma in relation to the interval between resection and death. Chest, 71, 725 .

WELLMANN, K.F., CHAFIAN, Y. \& EDELMAN, E. (1969). Small bowel perforation from solitary metastasis of clinically undetected pulmonary giant cell carcinoma. American Journal of Gastroenterology, 51, 145.

WINCHESTER, D.P., MERRILL, J.R., VICTOR, T.A. \& SCANLON, E.F. (1977). Small bowel perforation secondary to metastatic carcinoma of the lung, Cancer, 40, 410.

WOOTEN, D.G., MORGAN, S.C. \& HUGHES, R.K. (1967). Perforation of a metastatic bronchogenic carcinoma of the jejunum. Annals of Thoracic Surgery, 3, 57. 